\title{
MEASUREMENT OF CEREBRAL BLOOD FLOW DURING CARDIOPULMONARY BYPASS WITH NEAR-INFRARED SPECTROSCOPY
}

Idris G. Roberts, $\mathrm{BSc}^{\mathrm{a}}$

Penny Fallon, MRCP ${ }^{\mathrm{a}}$

Fenella J. Kirkham, FRCP

Paul M. Kirshbom, MD

Christopher E. Cooper, $\mathrm{PhD}^{\mathrm{d}}$

Martin J. Elliott, FRCS ${ }^{\mathrm{b}}$

A. David Edwards, FRCP
Objective: A novel noninvasive method for repeatedly measuring cerebral blood flow during cardiopulmonary bypass by near-infrared spectroscopy is described. The reproducibility of the method is investigated and a comparison is made with an established technique. Methods and results: The method is derived from the Fick principle and uses indocyanine green dye, injected into the bypass circuit, as an intravascular tracer. Cerebral blood flow was measured in nine children undergoing cardiopulmonary bypass on a total of 49 occasions. Results from this study suggest that an integrating period of 4 seconds provided a consistent measurement of global cerebral blood flow. The values obtained ranged from 3.2 to 32.4 (median 15.9 ) $\mathrm{ml} \cdot 100$ $\mathrm{gm}^{-1} \cdot \mathrm{min}^{-1}$. In an additional 10 children in whom repeated measurements were made, the coefficient of variation was $11 \% \pm 7 \%$ (mean \pm standard deviation). In a further study, the method was compared with microsphere injection in five piglets undergoing cardiopulmonary bypass. The comparison within each animal with the linear least squares method gave values for $R^{2}$ in the range 0.91 to 0.99 . The gradients of the fits ranged from 0.5 to 1.8 (median 1.0). The mean difference between the two techniques was 5.7 $\mathrm{ml} \cdot 100 \mathrm{gm}^{-1} \cdot \mathrm{min}^{-1}$ or $7 \%$. The coefficient of variation for the piglets was $14 \% \pm 9 \%$ (mean \pm standard deviation). Conclusions: Indocyanine green and near-infrared spectroscopy allow frequent and repeated measurements of cerebral blood flow during cardiopulmonary bypass. The measurements are reproducible and accurately reflect changes in cerebral blood flow. It may be widely applicable both in research and clinical practice. (J Thorac Cardiovasc Surg 1998;115:94-102)
$\mathrm{N}$ ear-infrared spectroscopy (NIRS) has previously been used to estimate cerebral blood flow ( $\mathrm{CBF}$ ) from the Fick principle by observing changes in oxyhemoglobin as an intravascular tracer in sick

Departments of Neurosciences ${ }^{\mathrm{a}}$ and Cardiothoracic Surgery, ${ }^{\mathrm{b}}$ Institute of Child Health (UCL) and Great Ormond Street Hospital for Children, Department of Paediatrics and Neonatal Medicine, Royal Postgraduate Medical School, ${ }^{\mathrm{c}}$ Department of Medical Physics and Bioengineering, University College London, London, United Kingdom, ${ }^{\mathrm{d}}$ and Department of Surgery Duke University Medical Center, Durham, N.C. ${ }^{\text {e }}$

C.E.C. is a Medical Research Council Training Fellow. This work was funded by the British Heart Foundation.

Received for publication June 23, 1997; revisions requested August 12, 1997; revisions received Sept. 15, 1997; accepted for publication Sept. 15, 1997.

Address for reprints: Idris Roberts, BSc, Biomedical Engineering Department, Great Ormond Street Hospital for Children, Great Ormond Street, London WC1 3JH, United Kingdom.

Copyright (C) 1998 by Mosby, Inc.

$0022-5223 / 98 \$ 5.00+0 \quad \mathbf{1 2 / 1 / 8 6 1 8 8}$ newborn infants receiving intensive care, ${ }^{1}$ healthy adults, ${ }^{2}$ and children undergoing cardiopulmonary bypass (CPB). ${ }^{3}$ However, the use of oxyhemoglobin makes assumptions about cerebral oxygen uptake that may not be appropriate during CPB. This article reports the use of an improved method that uses the optical dye indocyanine green (ICG) as an intravascular tracer.

\section{Materials and methods}

Theory 1: NIRS. Visible light is highly absorbed by tissue and thus can penetrate only a few millimetres. Near-infrared light, in the spectral range 700 to $1000 \mathrm{~nm}$, is absorbed less and can penetrate much further, up to 6 to $8 \mathrm{~cm}$ of brain. ${ }^{4}$ These optical properties allow transmission spectroscopy to be performed in vivo. ${ }^{5}$

For linear transillumination of tissue, the modified Beer-Lambert law can be expressed as ${ }^{6}$ :

$$
A=(a[c] L B)+G
$$

where $A$ is the attenuation of light in optical densities; $a$ is the extinction coefficient of the chromophore 


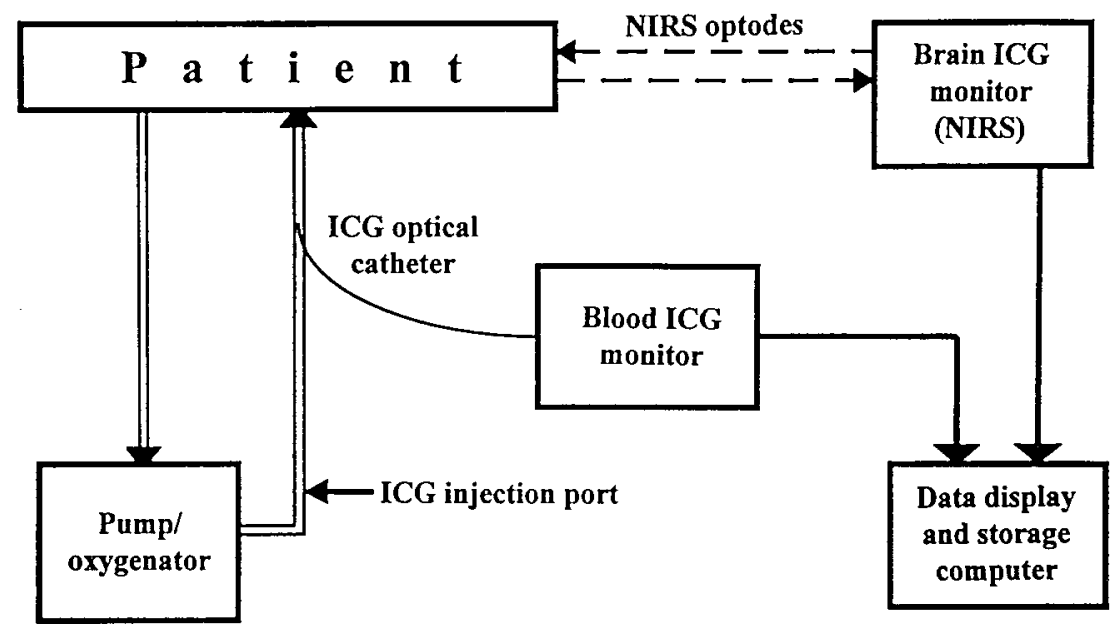

Fig. 1. Diagram showing the disposition of equipment for measurement of cerebral blood flow. The equipment is described in the text. ICG, Indocyanine green dye, NIRS, near-infrared spectrometer.

$\left(\mathrm{mmol}^{-1} \cdot \mathrm{L} \cdot \mathrm{cm}^{-1}\right) ;[c]$ is the concentration of chromophore $\left(\mathrm{mmol} \cdot \mathrm{L}^{-1}\right) ; L$ is the distance between points of light entry and exit $(\mathrm{cm}) ; B$ is a "pathlength factor" that takes account of the increased optical path caused by the scattering of light in the tissue; and $G$ is a factor related to tissue and optode geometry.

The attenuation caused by scattering and the geometric factor $(G)$ is usually unknown and thus [c] cannot be quantified absolutely. However, in a given tissue with fixed optical geometry it is likely to remain constant in the short term; thus changes in attenuation can be attributed solely to changes in the concentration of chromophore:

$$
\Delta[\mathrm{c}]=\Delta \mathrm{A} /(\mathrm{aLB})
$$

Scattering causes the distance traveled by the light to be greater than $\mathrm{L}$ by a factor $\mathrm{B}$, and the distance traveled is given by the product of $\mathrm{L}$ and $\mathrm{B}$. Provided these factors and the extinction coefficients of the chromophores present are known, changes in chromophore concentration can be quantified using equation 2 . This study used a value of $B$ of 4.39 for infants less than 2 years old and 5.93 for older children. ${ }^{4,7}$

In brain, the major endogenous chromophores that absorb light in the spectral range 700 to $1000 \mathrm{~nm}$ and whose concentrations change over the short term are oxyhemoglobin and deoxyhemoglobin and cytochrome oxidase. ${ }^{8}$ ICG is an exogenous chromophore that can be administered by injection. It is a tricarbocyanine dye of molecular weight 924.9 that absorbs near-infrared light maximally between 795 and $805 \mathrm{~nm}$. It has a low acute toxicity with a median lethal dose $\left(\mathrm{LD}_{50}\right)$ in mice of 650 $\mathrm{mg} \cdot \mathrm{kg}^{-1}$. The maximum recommended dose is 5 $\mathrm{mg} \cdot \mathrm{kg}^{-1}$. The dye is strongly protein bound to albumin in plasma and rapidly and completely eliminated by the liver, although excretion is slowed during cardiac operations. Full pharmacologic and toxicologic data are available, ${ }^{9}$ and a product license for the use of ICG is in force in the United States and the United Kingdom. Changes in the concentrations of these four chromophores can be calculated from observed changes in the attenuation of light at four wavelengths.

Theory 2: Measurement of CBF using NIRS. The Fick principle states that the rate of accumulation of a tracer substance in an organ (Q) is equal to the difference between the rate of arrival and the rate of departure of that substance. If a tracer is suddenly introduced into the arterial blood, a measurement of the amount accumulated in the organ can be made at a time (t) later. While $t$ is less than the minimum transit time of blood through the organ, the tracer will not appear in the venous efflux, and flow (f) can be measured as the ratio of tracer accumulated to the quantity of tracer introduced over the time period (t). The quantity of tracer introduced by time $t$ is equal to the integral of the change in the arterial concentration of tracer at time $t$ $(\mathrm{Pa}[\mathrm{t}])$ with respect to time. Thus:

$$
\mathrm{f}=\frac{\mathrm{Q}(\mathrm{t})}{\int_{0}^{t} \mathrm{~Pa}(\mathrm{t}) \mathrm{dt}}
$$

ICG can be injected into the CPB circuit and the concentration in blood entering the aorta measured by an optical device situated in the efferent limb of the bypass circuit. Because no further dilution of [ICG] occurs between this point and the brain, the concentration measured is the cerebral arterial concentration $\left(\Delta[\mathrm{ICG}]_{\text {blood }}\right)$, and the quantity of tracer introduced $(\mathrm{Pa}(\mathrm{t}))$ is given by the integral of $\Delta[\mathrm{ICG}]_{\text {blood }}$ with respect to time. The increase in ICG in the brain ( $\left.\Delta[\mathrm{ICG}]_{\text {brain }}\right)$ can be measured by NIRS; this quantifies the tracer accumulation $(\mathrm{Q}(\mathrm{t}))$. Thus: 
Table I. Clinical details

\begin{tabular}{|c|c|c|c|c|}
\hline Patient & $\begin{array}{l}\text { Age } \\
(\mathrm{mo})\end{array}$ & $\begin{array}{c}\text { Weight } \\
(\mathrm{kg})\end{array}$ & Diagnosis & Operation \\
\hline 1 & 6 & 5.6 & VSD & Patch closure of VSD \\
\hline 2 & 31 & 15.7 & $\begin{array}{l}\text { DORV, transposition, PS, VSD } \\
\text { (bidirectional Glenn at } 7 \text { mo) }\end{array}$ & TCPC \\
\hline 3 & 24 & 7.4 & Complex DORV & $\begin{array}{l}\text { Intraventricular tunnel, PA reconstruction, } \\
\text { RV-PA conduit }\end{array}$ \\
\hline 4 & 51 & 13.7 & TA/PS, VSD, ASD & $\mathrm{TCPC}$ \\
\hline 5 & 147 & 50.0 & & $\begin{array}{l}\text { Redo replacement of aortic prosthesis and } \\
\text { ileofemoral PTFE* graft }\end{array}$ \\
\hline 6 & 1 & 3.4 & TGA & Arterial switch \\
\hline 7 & 8 & 6.5 & Tetralogy of Fallot & Fallot repair \\
\hline 8 & 19 & 8.6 & $\begin{array}{l}\text { PA, large ASD, narrow aortic } \\
\text { arch }\end{array}$ & $\begin{array}{l}\text { Glenn shunt reconstruction RPA; pulmo- } \\
\text { nary valve homograft }\end{array}$ \\
\hline 9 & 34 & 12.8 & Partial AVSD & Repair AVSD \\
\hline
\end{tabular}

$A S D$, Atrial septal defect; $A V S D$, atrioventricular septal defect; $D O R V$, double outlet right ventricle; $P A$, pulmonary artery; $P S$, pulmonary stenosis; $R P A$, right pulmonary artery; $R V$, right ventricle; $T A$, tricuspid atresia; $T C P C$, total cavopulmonary connection; TGA, transposition of great arteries; VSD, ventricular septal defect.

*PTFE (polytetrafluoroethylene). A Gore-Tex vascular graft, registered trademark of W.L. Gore \& Associates, Inc., Newark, Delaware.

$$
\mathrm{CBF}=\frac{\mathrm{k}\left(\Delta[\mathrm{ICG}]_{\text {brain }}\right)}{\int_{0}^{t}[\mathrm{ICG}]_{\text {blood }} \mathrm{dt}} \mathrm{ml} \cdot 100 \mathrm{gm}^{-1} \cdot \mathrm{min}^{-1}
$$

where $k$ is a constant reflecting the molecular weight of ICG, as well as tissue density and decimal conversions that allow blood flow to be expressed per $100 \mathrm{gm}$ of tissue.

Theory 3: Estimation of mean cerebral transit time. Mean transit time (MTT) can be calculated after a rapid injection of nondiffusable tracer by the "height over area" method..$^{10}$ The MTT is related to CBF and cerebral blood volume (CBV) by the Stewart-Hamilton equation:

$$
\mathrm{MTT}=\frac{\mathrm{CBV}}{\mathrm{CBF}}
$$

Measurement of CBF with NIRS. Fig. 1 shows the apparatus used to measure $\mathrm{CBF}$ during $\mathrm{CPB}$. Nearinfrared light was carried from the NIRS spectrometer (NIRO 500; Hamamatsu Photonics KK, Hamamatsu City, Japan) to the head by a fiberoptic bundle (optode) placed against the skin overlying the parietal region of the brain at least $3.5 \mathrm{~cm}$ apart and held by an elastic bandage underneath a cover to reduce background light. The light transmitted across the head was collected by a second optode and carried back to the spectrometer, which used pulsed laser diodes at 4 wavelengths $(776,819,843$, and $913 \mathrm{~nm}$ ) as light sources; changes in light attenuation were measured every half second. The algorithm used to calculate the changes in concentrations of the chromophores incorporated a linear least squares curve fitting technique. ${ }^{11,12}$ The extinction coefficients used in the algorithm were corrected for the wavelength dependence of pathlength using the method of Essenpreis. ${ }^{12}$ The correction factors for the wavelengths used were 0.9995, 0.9550, 0.9162 , and 0.7805 (M. Cope, personal communication, October 1994).
An optical catheter for measuring $[\mathrm{ICG}]_{\text {blood }}$ (PV2024; Pulsion Medizintechnik, Munich, Germany) was inserted into the CPB circuit just proximal to the aorta. ICG (Pulsion Medizintechnik, Munich, Germany), $0.1 \mathrm{mg} \cdot \mathrm{kg}^{-1}$, was injected into the bypass circuit and the concentration of tracer in blood entering the body was quantified optically by a dye densitometer (model IVH4; Pulsion Medizintechnik, Munich, Germany) to provide a measure of the arterial concentration of tracer.

Study protocols. Studies were approved by the Research Ethics Committees of Great Ormond Street Hospital for Children (November 1991) and of Duke University (March 1994), and consent was obtained from the parents of the children studied.

All animals received humane care in compliance with the "Guide for the Care and Use of Laboratory Animals" published by the National Institutes of Health.

Measurement of $C B F$ and MTT in children. Nine children undergoing CPB surgery for congenital heart disease were studied. The diagnosis and physiologic details are given in Table I. The pump flow was variable but was maintained at $2.4 \mathrm{~L} \cdot \mathrm{min}^{-1} \cdot \mathrm{m}^{-2}$ whenever possible. CBF and MTT were measured in all patients.

Reproducibility in children. Ten children undergoing CPB operations for congenital heart disease were studied. The diagnosis and physiologic details are given in Table II. During periods of stability, groups of between three and six $\mathrm{CBF}$ measurements were made. Reproducibility was assessed by calculating the coefficient of variation and by performing analysis of variance with child as a factor and time as a covariate to allow for any effect of differing pump flow and temperature.

Comparison with microspheres in an animal model. Five newborn piglets were premedicated with ketamine (20 $\left.\mathrm{mg} \cdot \mathrm{kg}^{-1}\right)$ and acepromazine $\left(1 \mathrm{mg} \cdot \mathrm{kg}^{-1}\right)$ and ventilated mechanically (Sechrist infant ventilator, model IV-100B, Sechrist Industries Inc., Anaheim, Calif.). They were then 
Table II. Clinical details

\begin{tabular}{crcll}
\hline Patient & $\begin{array}{c}\text { Age } \\
(\mathrm{mo})\end{array}$ & $\begin{array}{c}\text { Weight } \\
(\mathrm{kg})\end{array}$ & \multicolumn{1}{c}{ Diagnosis } & \multicolumn{1}{c}{ Operation } \\
\hline 1 & 17 & 11.3 & Tricuspid regurgitation & Tricuspid valve replacement \\
2 & 5 & 3.9 & VSD & Patch closure of VSD \\
3 & 13 & 9.3 & Tetralogy of Fallot & Fallot repair \\
4 & 149 & 46 & Aortic incompetence & Aortic valve replacement \\
5 & 4 & 4.9 & Tetralogy of Fallot & Fallot repair \\
6 & 55 & 18.5 & AVSD & Patch of ASD \\
7 & 35 & 12.5 & Truncus arteriosus & Truncus repair \\
8 & 36 & 12.9 & ASD & Closure of ASD \\
9 & 49 & 15.5 & Complex heart, PA & Fontan \\
10 & 2 & 4.6 & VSD & VSD closure
\end{tabular}

$A S D$, Atrial septal defect; $A V S D$, atrioventricular septal defect; $P A$, pulmonary atresia; $V S D$, ventricular septal defect.

anesthetized with intravenous fentanyl $\left(100 \mu \mathrm{g} \cdot \mathrm{kg}^{-1}\right.$ bolus and $50 \mu \mathrm{g} \cdot \mathrm{kg}^{-1}$ per hour infusion), paralyzed with pancuronium $\left(0.3 \mathrm{mg} \cdot \mathrm{kg}^{-1}\right)$, and placed on CPB. Systematically, to induce measurable changes in $\mathrm{CBF}$, pump flow and body temperature were changed. Injections of $15 \mu \mathrm{m}$ radioactive microspheres were made at (1) pump flow of $100 \mathrm{ml} \cdot \mathrm{kg}^{-1} \cdot \mathrm{min}^{-1}$ and temperature of $37^{\circ} \mathrm{C}$; (2) $100 \mathrm{ml} \cdot \mathrm{kg}^{-1} \cdot \mathrm{min}^{-1}, 22^{\circ} \mathrm{C}$; (3) $50 \mathrm{ml} \cdot$ $\mathrm{kg}^{-1} \cdot \mathrm{min}^{-1}, 22^{\circ} \mathrm{C}$; (4) $50 \mathrm{ml} \cdot \mathrm{kg}^{-1} \cdot \mathrm{min}^{-1}, 17^{\circ} \mathrm{C}$; and (5) $25 \mathrm{ml} \cdot \mathrm{kg}^{-1} \cdot \mathrm{min}^{-1}, 17^{\circ} \mathrm{C}$. Microspheres $\left(3 \times 10^{6}\right.$ in $1 \mathrm{ml} 10 \%$ dextran and $0.01 \%$ Tween, ${ }^{153} \mathrm{Gd},{ }^{113} \mathrm{Sn}$, ${ }^{103} \mathrm{Ru},{ }^{95} \mathrm{Nb}$, and ${ }^{46} \mathrm{Sc}$ in random order; NEN Research Products, DuPont, Wilmington, Del.) were injected into a left atrial catheter. Blood was withdrawn from the femoral arterial catheter at a rate of $7 \mathrm{ml} \cdot \mathrm{min}^{-1}$ over 120 seconds starting 10 seconds before the injection. Measurements of CBF using ICG as a tracer were made simultaneously with the microsphere injection as described above; one optode was placed over the frontal region and the other over the parietal region, both on the right side. At each of five pump flow and temperature settings, a microsphere CBF was compared with the mean of 3 to 7 (median 4) ICG CBF measurements.

At the end of the study the animals were killed, and the brain was harvested. The brain was subdivided into the cortex, basal ganglia, cerebellum, and brain stem. All the samples were counted in a gamma counter (Minaxi Autogamma Counter, 5000 Series, Packard Instrument Co., Meriden, Conn.), and individual nuclide activity was calculated (Compusphere Microsphere Multinuclide Analysis Software, Packard Instrument Co.).

The mean CBF value of the repeated NIRS measurements $(\mathrm{t}=4$ seconds) was compared with the CBF value calculated for cortex flow by the microsphere method. Cortex flow was chosen for comparison because it is believed that the near-infrared technique probably reflects cortical flow because of the penetrance of light. The mean, median, and range of the differences were calculated. Reproducibility was assessed from the coefficient of variation and by performing an analysis of variance with pig as a factor and time as a covariate.

\section{Results}

ICG CBF and MTT in children. Fig. 2 shows a typical example of an NIRS measurement of CBF. One to nine (median five) measurements of $\mathrm{CBF}$ were made in each child, and the interval between measurements ranged from 2.7 to 67.6 minutes, median 13 minutes. Each measurement of $\mathrm{CBF}$ and MTT took less than 10 seconds and could be repeated within 3 minutes. Fig. 3 gives the results of the measurements of CBF and MTT.

The effect of calculating tracer accumulation over different periods from 2 to 6 seconds is shown in Fig. 4. Median $\mathrm{CBF}$ in each infant ranged from 8.0 to 67.7 (median 23.5) $\mathrm{ml} \cdot 100 \mathrm{gm}^{-1} \cdot \mathrm{min}^{-1}$ for calculations where $t=2$ seconds. When a greater proportion of flow from longer transit time compartments was included by increasing $t$ to 4 seconds (see discussion), CBF ranged from 8.2 to 32.4 (median 15.9) $\mathrm{ml} \cdot 100 \mathrm{gm}^{-1} \cdot \mathrm{min}^{-1}$.

Reproducibility of ICG CBF in children. One to four (median three) groups of three to six (median four) CBF measurements were made in each child. For the whole group, temperature ranged from $15.9^{\circ}$ to $38.2^{\circ} \mathrm{C}$, and pump flow ranged from 50 to 200 $\mathrm{ml} \cdot 100 \mathrm{gm}^{-1} \cdot \mathrm{min}^{-1}$. The time between measurements within a group ranged from 0.5 to 7.4 (median 2.0) minutes. The time between groups ranged from 16.7 to 78.7 (median 30.3) minutes. The group mean CBFs ranged from 3.2 to 70.7 (median 11.9) $\mathrm{ml} \cdot 100$ $\mathrm{gm}^{-1} \cdot \mathrm{min}^{-1}$. For the repeated measurements, the coefficient of variation was $11 \% \pm 7 \%$. Analysis of variance showed that the interindividual differences and the effects of different pump flows and temperatures accounted for $73 \%$ of the variability; the residual variability (27\%) includes the reproducibil- 

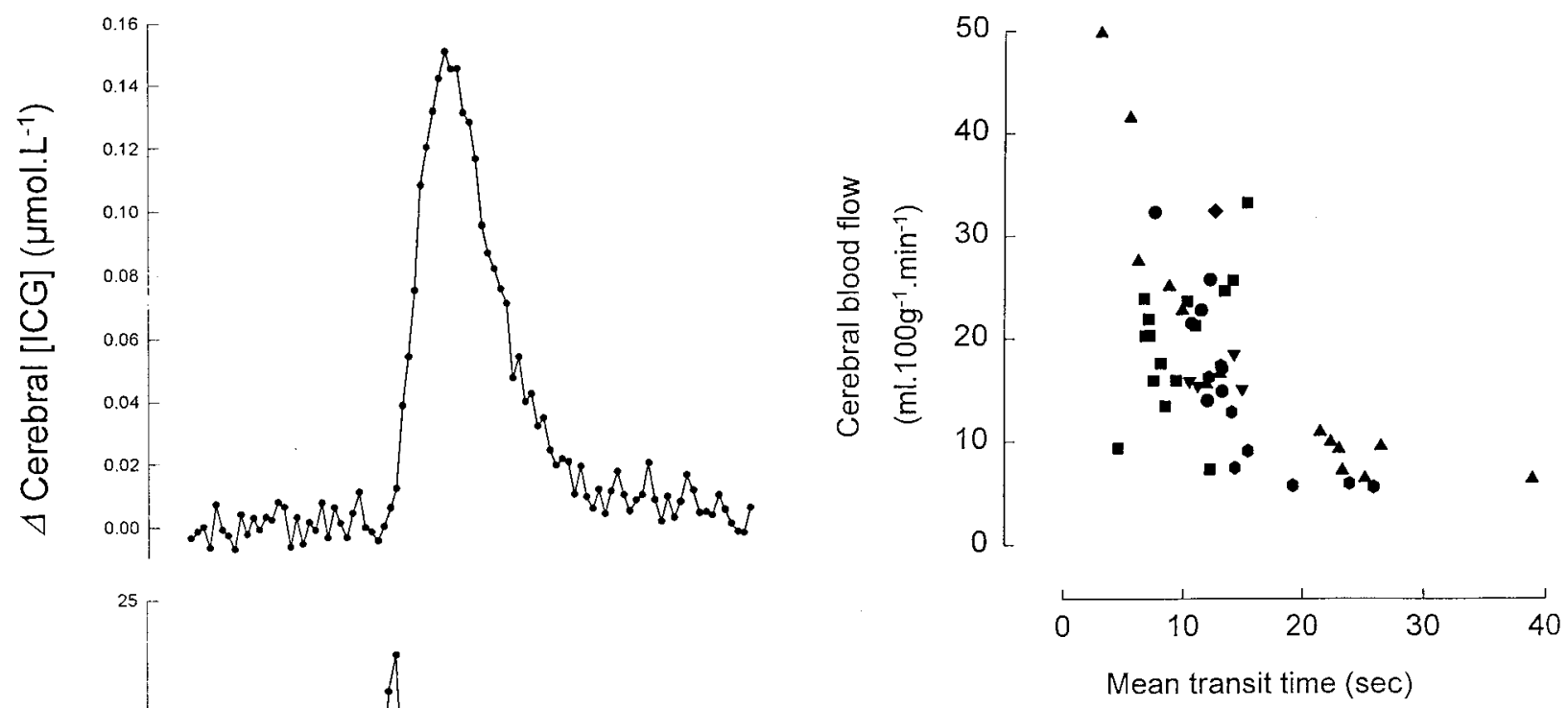

Fig. 3. Values for cerebral blood flow and mean transit time obtained in nine infants during CPB operation. Each infant is represented by a different symbol.

The coefficient of variation was $14 \% \pm 9 \%$. Analysis of variance showed that the effects of interindividual variation, temperature, and pump flow accounted for $84 \%$ of the variability.

\section{Discussion}

Accuracy of NIRS. Precise determination of changes in [ICG] requires (1) accurate data for the absorption spectra of all mobile chromophores present; (2) that the modified Beer-Lambert relationship is valid; (3) that the scattering properties of the tissue under interrogation are known so that the differential pathlength factor (DPF) for transport of light can be estimated accurately; and (4) that there is accurate analysis of absorption changes. These will be considered in turn.

Near-infrared spectra for hemoglobin and cytochrome oxidase have been measured under carefully controlled conditions by several groups. ${ }^{13-15}$ Spectra measured in vivo and in vitro are identical and confirmed that the brain normally contains only three mobile chromophores. ${ }^{8,11}$ Because the exogenous tracer molecule ICG is strongly proteinbound in vivo, we have now measured absorption spectra for ICG in the presence of plasma protein (see Appendix Table I).

The validity of the modified Beer-Lambert law in biologic tissue has been demonstrated both by theoretical modeling and experimental measurement. ${ }^{6}$ 


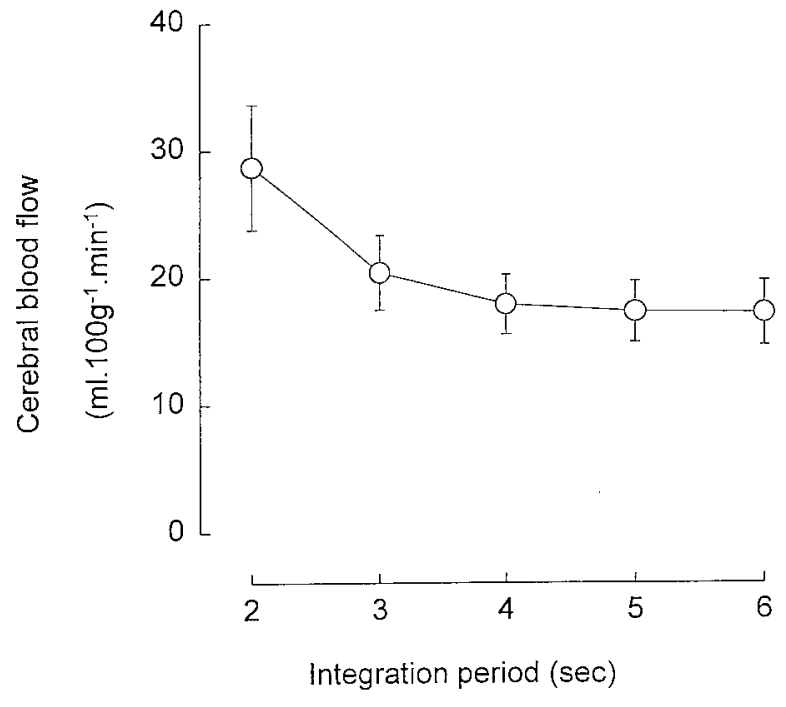

Fig. 4. Graph relating values for $\mathrm{CBF}$ to the integration period $\mathrm{t}$ in 49 measurements in nine infants. Inhomogeneity of flow is demonstrated, with shorter integration periods leading to higher measured values in some infants.

The scattering properties of adult brain in vivo and postmortem neonatal brain have been measured, and the extinction coefficients used in the conversion algorithm are corrected for the measured variation in the scattering of light by cerebral tissue at different wavelengths. ${ }^{4}$ We have used the DPF measured in infants for children up to 2 years of age and for adults above that age based on an estimation of the amount of myelin in the developing brain. This will introduce some inaccuracy into our results that will be corrected in the future when routine measurements of the pathlength of light become available. Technology has recently been developed that will allow pathlength to be measured routinely by phase modulation during all NIRS procedures. ${ }^{16}$

Measurements of changes in the attenuation of light at four wavelengths were analyzed using a linear least squares technique. Other workers have demonstrated that the errors induced by using this technique are very small. ${ }^{17}$ System noise and systematic error are a small fraction of the total signal. ${ }^{18}$

Measurement of CBF by NIRS. The use of ICG as an intravascular tracer rests on several assumptions. It is assumed (1) that the tracer is not consumed by the organ, (2) that the flow to the organ remains constant, (3) that the total volume of blood in the organ remains constant, (4) that
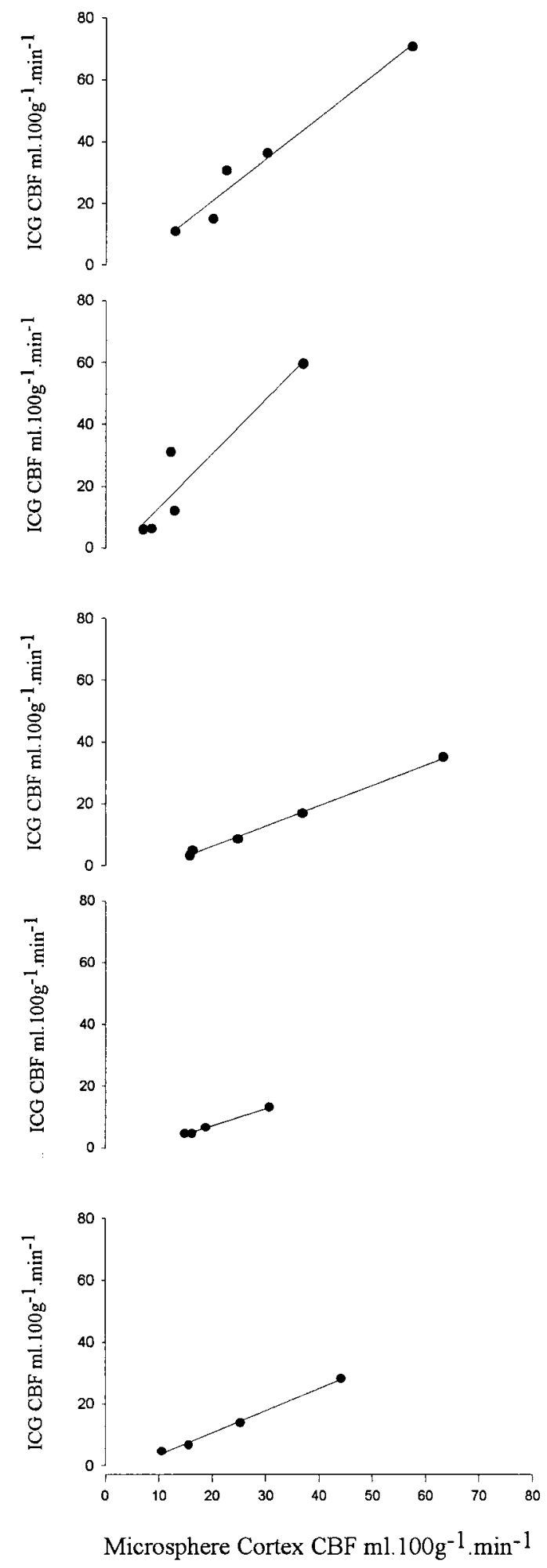

Fig. 5. Graphs showing the relation between CBF measured by the ICG method and cortical flow measured with microspheres for each animal. 
there is no further admixture of blood beyond the point of $[\mathrm{ICG}]_{\text {blood }}$ measurement in the bypass circuit, and (5) that the measurement is made over a time period less than the minimum transit time of the tracer through the organ. These will be addressed in turn.

ICG is an inert substance that is not consumed by the brain.

The assumption of constant blood flow is required for all methods of CBF measurement, but it poses less of a problem for the present method, where a measurement requires only 4 to 6 seconds, than for conventional methods such as the Kety-Schmidt technique, or measurements of ${ }^{133} \mathrm{Xe}$ clearance, which assume constant flow for 10 minutes or more, a condition unlikely to be met during CPB.

Constant CBV is also assumed by other measurement techniques. NIRS measures changes in total cerebral hemoglobin concentration, which is directly related to CBV. Thus any change in CBV during measurement of $\mathrm{CBF}$ can be observed and the measurement disregarded. This is not possible with other methods for estimation of CBF.

Any admixture of blood beyond the point of $[\mathrm{ICG}]_{\text {blood }}$ measurement would cause CBF to be underestimated. However, this is extremely unlikely to occur given the placement of the efferent catheter from the pump-oxygenator.

$\mathrm{CBF}$ measurements should be completed in less than the minimum transit time of blood through the organ for quantification of the total amount of tracer accumulated. Although minimum transit time was not measured in our subjects, values obtained for MTT were much higher than the chosen values for $t$, suggesting that only trivial volumes of blood would have passed through the brain in less than the measurement period.

Inhomogeneity of CBF. The period of integration $t$ is chosen with respect to the distribution of transit times within the organ and should be explicit because any specific $t$ weights the measured value to a particular distribution of blood flow. ${ }^{19}$ Low values for $t$ will measure the flow of blood that passes through the brain with a short transit time, whereas higher values for $t$ will include components of total $\mathrm{CBF}$ with longer transit times. Comparison of values for CBF calculated for values of $t$ between 2 and 6 seconds $^{1,2}$ revealed predictable inhomogeneity of flow within the brain (Fig. 4).

CBFs calculated over shorter periods were generally higher than flow compartments of longer transit time. The value of $\mathrm{CBF}$ obtained will thus be modulated by the value chosen for t. Measurements that use fewer points on the tracer accumulation curve have larger variability, ${ }^{19}$ and studies of adult volunteers using oxyhemoglobin as a tracer, ${ }^{19}$ as well as inspection of Fig. 4, suggest that integration more than 4 seconds provides a stable and consistent measurement of global CBF.

Cerebral blood flow and MTT. Measurement of CBF requires only the first few seconds of tracer accumulation, but if the full period of tracer passage through the brain is observed, MTT can be calculated by conventional methods. ${ }^{20}$ The inverse relation between CBF and MTT predicted by the Stewart-Hamilton equation was found and is shown in Fig. 3.

Comparison studies. The coefficient of variation for the studies in children and in piglets were comparable with values for other methods of measuring CBF. The fit within each piglet as estimated by $R^{2}$ is good. However, the slopes of the fits are variable. It is known from measurements in human beings that the DPF varies considerably between subjects. ${ }^{4,16}$ However, to account for all the variation in slope found here, a standard deviation of $50 \%$ of the mean DPF would be required. The $R^{2}$ for each animal implies good agreement on change for percentage flow change between the two methods across a wide range of temperature and pump flow values. This would suggest that for one subject the DPF value remains constant across the range of $\mathrm{CPB}$ conditions even though it may be subject to intersubject variation.

Technical difficulties and assumptions exist for all CBF techniques, including those using microspheres, and these may become even more important during CPB. The microsphere technique measures regional $\mathrm{CBF}$ as the NIRS method is also considered to do. An inherent variability exists in both the microsphere technique (of $10 \%$ to $20 \%$ ) and in the NIRS method that may account for some of the discrepancy between them. In addition, the NIRS technique may interrogate a variable contribution from tissues not accounted for in any of the microsphere measurements, such as skull and skin.

Clinical value of $\mathrm{CBF}$ measurements during $\mathrm{CPB}$. A significant number of children and adults who undergo CPB operations survive with neurodevelopmental or intellectual impairment, probably caused by perioperative derangements of $\mathrm{CBF}^{21}$ The method described here should allow multiple measurements of $\mathrm{CBF}$ to be made during a single operating session and permit $\mathrm{CBF}$, as well as other variables such as CBV, MTT, cerebral oxygen, and 
glucose delivery, to be routinely measured. It may be possible to define critical levels of CBF that should trigger appropriate responses from physicians caring for patients during surgery to prevent ischemic injury from occurring.

Future developments. The technique detailed here requires validation, perhaps comparing with the Kety-Schmidt technique, under the special conditions of CPB surgery, both in children and in adult patients. Improvements in the accuracy of the technique can be expected as NIRS technology improves, for example with the introduction of continuous measurement of the optical pathlength. ${ }^{22}$ Use of NIRS allows the acquisition of other data on cerebral oxygenation simultaneously during $\mathrm{CBF}$ measurements, ${ }^{3}$ and there is also the prospect of regional flow estimations when NIRS localization becomes available. ${ }^{23}$

We thank Dr. R. Ungerleider, Department of Surgery, Duke University Medical Center, Durham, North Carolina, for his collaborative support; Angie Wade, Department of Biostatistics, Institute of Child Health (UCL), London, United Kingdom, for statistical advice; and Pulsion Medizintechnik for the loan of a model IVH4 intravascular fibreoptic dye densitometer.

\section{REFERENCES}

1. Edwards AD, Wyatt JS, Richardson C, Delpy DT, Cope M, Reynolds EO. Cotside measurement of cerebral blood flow in ill newborn infants by near infrared spectroscopy. Lancet 1988;2:770-1.

2. Elwell CE, Cope M, Edwards AD, Wyatt JS, Delpy DT, Reynolds EO. Quantification of adult cerebral hemodynamics by near-infrared spectroscopy. J Appl Physiol 1994;77: 2753-60.

3. Fallon P, Roberts I, Kirkham FJ, et al. Cerebral hemodynamics during cardiopulmonary bypass in children using near-infrared spectroscopy. Ann Thorac Surg 1993; 56:1473-7.

4. van der Zee P, Cope M, Arridge SR, et al. Experimentally measured optical pathlengths for the adult head, calf and forearm and the head of the newborn infant as a function of interoptode spacing. Adv Exp Med Biol 1992;316:143-53.

5. Jobsis FF. Noninvasive infrared monitoring of cerebral and myocardial oxygen sufficiency and circulatory parameters. Science 1977;198:1264-7.

6. Delpy DT, Cope M, van der Zee P, Arridge S, Wray S, Wyatt J. Estimation of optical pathlength through tissue from direct time of flight measurement. Phys Med Biol 1988;33:1433-42.

7. Wyatt JS, Cope M, Delpy DT, et al. Measurement of optical path length for cerebral near infrared spectroscopy in newborn infants. Dev Neurosci 1990;12:140-4.

8. Araki R, Nashimoto I. I. Multicomponent analysis of near infrared spectra of anaesthatised rat head. II. Quantitative multivariate analysis of haemoglobin and cytochrome oxidase by nonnegative least squares method. Adv Exp Med Biol 1990;248:11-20.

9. Anonymous. ICG-PULSION Drug Information. Pulsion Medizintechnik, Munich, Germany. 1994.

10. Zieder KL. Equation for measuring blood flow by external monitoring of radioisotopes. Circ Res 1965;16:309-21.

11. Cope M. The development of a near infrared spectroscopy system and its applications for non-invasive monitoring of cerebral blood and tissue oxygenation in the newborn infant. PhD Thesis, University of London. 1991.

12. Essenpreis M, Cope M, Elwell CE, Arridge SR, van der Zee P, Delpy DT. Wavelength dependence of the differential pathlength factor and the log slope in time-resolved tissue spectroscopy. Adv Exp Med Biol 1993;333:9-20.

13. Cope M, Delpy DT, Wray S, Wyatt JS, Reynolds EO. A CCD spectrophotometer to quantitate the concentration of chromophores in living tissue utilising the absorption peak of water at $975 \mathrm{~nm}$. Adv Exp Med Biol 1989;248:33-40.

14. Wray S, Cope M, Delpy DT, Wyatt JS, Reynolds EO. Characterization of the near infrared absorption spectra of cytochrome aa3 and haemoglobin for the non-invasive monitoring of cerebral oxygenation. Blochim Biophys Acta 1988; 933:184-92.

15. Zijlstra WG, Buursma A, Meeuwsen-van der Roest WP. Absorption spectra of human fetal and adult oxyhaemoglobin, deoxyhaemoglobin, carboxyhaemoglobin and methaemoglobin. Clin Chem 1991;37:1633-8.

16. Duncan A, Meek JH, Clemence M, et al. Measurement of cranial optical path length as a function of age using phase resolved near infrared spectroscopy. Pediatr Res 1996;39: 889-94.

17. Cope M, van der Zee P, Essenpreis M, Arridge SR, Delpy DT. Data analysis methods for near infrared spectroscopy of tissue: problems of determining the relative cytochrome aa3 concentration. Proc SPIE 1991;1431:251-62.

18. Edwards AD, Brown GC, Cope M, et al. Quantification of concentration changes in neonatal human cerebral oxidized cytochrome oxidase. J Appl Physiol 1991;71:1907-13.

19. Elwell CE, Cope M, Edwards AD, Wyatt JS, Reynolds EO, Delpy DT. Measurement of cerebral blood flow in adult humans using near infrared spectroscopy: methodology and possible errors. Adv Exp Med Biol 1992;317:235-45.

20. Colacino JM, Grubb B, Jobsis FF. Infra-red method for cerebral blood flow: comparison with ${ }^{133}$ Xenon clearance. Neurol Res 1981;3:17-31

21. Govier A. Central nervous system complications after cardiopulmonary bypass. In: Tinker JH, editor. Cardiopulmonary bypass: current concepts and controvesies. Philadelphia: WB Saunders; 1989.

22. Chance B, Maris M, Sorge J, Zhang MZ. A phase modulation system for dual wavelength difference spectroscopy of haemoglobin deoxygenation in tissues. Proc SPIE 1990;1204:481-91.

23. Arridge SR, van der Zee P, Cope M, Delpy DT. Reconstruction methods for infrared absorption imaging. Proc SPIE 1991;1431:204-15. 
Appendix Table I. Specific extinction coefficients of indocyanine green in 1\% bovine serum albumin solution.

\begin{tabular}{|c|c|c|c|c|c|}
\hline $\begin{array}{l}\text { Wavelength } \\
\quad(\mathrm{nm})\end{array}$ & $\begin{array}{c}I C G \\
\left(\mathrm{mmol}^{-1} \cdot \mathrm{L} \cdot \mathrm{cm}^{-1}\right)\end{array}$ & $\begin{array}{l}\text { Wavelength } \\
\text { (nm) }\end{array}$ & $\begin{array}{c}I C G \\
\left(\mathrm{mmol}^{-1} \cdot \mathrm{L} \cdot \mathrm{cm}^{-1}\right)\end{array}$ & $\begin{array}{l}\text { Wavelength } \\
\text { (nm) }\end{array}$ & $\begin{array}{c}I C G \\
\left(\mathrm{mmol}^{-1} \cdot \mathrm{L} \cdot \mathrm{cm}^{-1}\right)\end{array}$ \\
\hline 750 & 87.749 & 808 & 161.148 & 866 & 7.719 \\
\hline 752 & 89.299 & 810 & 155.574 & 868 & 7.202 \\
\hline 754 & 90.373 & 812 & 148.850 & 870 & 6.877 \\
\hline 756 & 91.468 & 814 & 141.097 & 872 & 6.376 \\
\hline 758 & 92.836 & 816 & 132.440 & 874 & 6.131 \\
\hline 760 & 94.485 & 818 & 123.420 & 876 & 5.902 \\
\hline 762 & 96.705 & 820 & 114.057 & 878 & 5.709 \\
\hline 764 & 99.322 & 822 & 104.226 & 880 & 5.363 \\
\hline 766 & 102.342 & 824 & 94.242 & 882 & 5.169 \\
\hline 768 & 105.755 & 826 & 85.140 & 884 & 5.148 \\
\hline 770 & 109.317 & 828 & 75.993 & 886 & 4.986 \\
\hline 772 & 113.466 & 830 & 67.463 & 888 & 4.781 \\
\hline 774 & 117.926 & 832 & 59.916 & 890 & 4.569 \\
\hline 776 & 122.538 & 834 & 52.489 & 892 & 4.427 \\
\hline 778 & 127.457 & 836 & 45.876 & 894 & 4.422 \\
\hline 780 & 132.638 & 838 & 40.023 & 896 & 4.332 \\
\hline 782 & 137.606 & 840 & 34.921 & 898 & 4.296 \\
\hline 784 & 142.903 & 842 & 30.298 & 900 & 4.076 \\
\hline 786 & 148.113 & 844 & 26.466 & 902 & 4.034 \\
\hline 788 & 153.212 & 846 & 23.030 & 904 & 4.073 \\
\hline 790 & 157.682 & 848 & 20.107 & 906 & 4.060 \\
\hline 792 & 161.981 & 850 & 17.575 & 908 & 4.041 \\
\hline 794 & 165.409 & 852 & 15.477 & 910 & 3.957 \\
\hline 796 & 168.067 & 854 & 13.624 & 912 & 3.892 \\
\hline 798 & 169.906 & 856 & 12.239 & 914 & 4.084 \\
\hline 800 & 170.695 & 858 & 10.991 & 916 & 4.040 \\
\hline 802 & 170.149 & 860 & 9.858 & 918 & 4.191 \\
\hline 804 & 168.306 & 862 & 9.006 & 920 & 4.287 \\
\hline 806 & 165.387 & 864 & 8.322 & 922 & 4.293 \\
\hline
\end{tabular}

